\title{
Qualidade de vida relacionada à saúde em pacientes pós-Covid-19: uma revisão
}

\section{sistemática}

\author{
Health-related quality of life in post-Covid-19 patients: a systematic review \\ Calidad de vida relacionada con la salud en pacientes post-Covid-19: una revisión sistemática
}

Recebido: 18/11/2021 | Revisado: 23/11/2021 | Aceito: 24/11/2021 | Publicado: 25/11/2021

Geovana de Sousa Nunes

ORCID: https://orcid.org/0000-0002-2877-9760 Centro Universitário Santo Agostinho, Brasil E-mail: geovanasnunes@ outlook.com

Maria Léia Raquel Silva Bento

ORCID: https://orcid.org/0000-0002-0091-3286 Centro Universitário Santo Agostinho, Brasil E-mail: marialeiaraquel@ hotmail.com

Saulo Araújo de Carvalho

ORCID: https://orcid.org/0000-0002-6705-1879 Centro Universitário Santo Agostinho, Brasil E-mail: sauloriverpi@gmail.com

\begin{abstract}
Resumo
O contágio pelo vírus SARS-CoV-2 é uma das infecções mais recentes explanadas nas ciências médicas, desde os relatórios iniciais, esse vírus trouxe consigo grande preocupação pela rapidez na sua transmissão e disseminação coincidindo com o agravamento dos sintomas, como a febre, tosse, fadiga, dispneia, dor de cabeça, tontura, diarreia e vômito. Quando se refere à saúde, a qualidade de vida inclui a satisfação e o bem-estar de acordo com a concepção do paciente, e essa qualidade de vida é afetada por doenças e futuras consequências. O objetivo do estudo foi evidências atuais sobre o impacto da Covid-19 na qualidade de vida e saúde de pacientes após a doença. Trata-se de uma revisão sistemática com abordagem qualitativa, onde baseou-se em um levantamento literário científico, que levou para uma análise, identificação e descrição do estudo. O estudo mostra que a Covid-19 provoca alterações na qualidade de vida e saúde dos pacientes de diferentes formas, dependendo da gravidade da doença, de complicações provocadas pela Covid-19, de como foi a internação do paciente, e também das suas próprias características que podem influenciar na gravidade da doença. Conclui-se que a Covid-19 tem impacto na qualidade de vida dos pacientes após a doença levando a uma piora significativa da saúde física e mental que pode persistir durante meses.
\end{abstract}

Palavras-chave: Covid-19; SARS-CoV-2; Qualidade de vida, Internação Hospitalar.

\begin{abstract}
Contagion by the SARS-CoV-2 virus is one of the most recent diseases explained in medical sciences, since the initial reports, this virus has brought great concern due to its rapid transmission and dissemination, coinciding with the worsening of symptoms, such as fever, cough, fatigue, dyspnoea, headache, dizziness, diarrhea and vomiting. When referring to health, a quality of life includes satisfaction and well-being according to the patient's conception, and this quality of life is affected by diseases and future consequences. The aim of the current study was on the impact of Covid-19 on the quality of life and health of patients after illness. This is a systematic review with a qualitative approach, which was based on a scientific literary survey, which led to an analysis, identification and description of the study. The study shows that Covid-19 causes changes in the quality of life and health of patients in different ways, depending on the severity of the disease, the complications caused by Covid-19, how the patient was hospitalized, and also their own characteristics which can cause the severity of the disease. It is concluded that Covid-19 has an impact on the quality of life of patients after the disease, leading to a significant deterioration in physical and mental health that can persist for months.
\end{abstract}

Keywords: Covid-19, SARS-CoV-2; Quality of life; Hospital Admission.

\section{Resumen}

El contagio por el virus SARS-CoV-2 es una de las infecciones más recientes explicadas en las ciencias médicas, desde los informes iniciales, este virus ha traído consigo una gran preocupación por la velocidad de su transmisión y propagación coincidiendo con el agravamiento de los síntomas. tales como fiebre, tos, fatiga, disnea, dolor de cabeza, mareos, diarrea y vómitos. Al referirse a la salud, la calidad de vida incluye la satisfacción y el bienestar según la concepción del paciente, y esta calidad de vida se ve afectada por enfermedades y consecuencias futuras. El objetivo 
del estudio fue la evidencia actual sobre el impacto de Covid-19 en la calidad de vida y la salud de los pacientes después de la enfermedad. Se trata de una revisión sistemática con enfoque cualitativo, que se basó en un relevamiento científico literario, que condujo al análisis, identificación y descripción del estudio. El estudio muestra que el Covid-19 provoca cambios en la calidad de vida y salud de los pacientes de diferentes formas, dependiendo de la gravedad de la enfermedad, las complicaciones ocasionadas por el Covid-19, la forma en que el paciente fue hospitalizado, y también de las propias características que puede influir en la gravedad de la enfermedad. Se concluye que Covid-19 tiene un impacto en la calidad de vida de los pacientes tras la enfermedad, provocando un importante deterioro de la salud física y mental que puede persistir durante meses.

Palabras clave: Covid-19, SARS-CoV-2; Calidad de vida; Admisión Hospitalaria.

\section{Introdução}

No dia 31 de dezembro de 2019 em Wuhan capital da província de Hubei (China), foi informado pelo governo chinês o primeiro caso de Covid-19. Após essa data, foram notificados cada vez mais casos da doença em províncias da china e em todos os países do mundo. O Brasil foi o primeiro país da América Latina a registrar um caso (26 de fevereiro de 2020), e a primeira morte foi registrada na Argentina (7 de março de 2020). Os primeiros casos apresentados eram relacionados a pessoas que realizaram alguma viagem, logo após, sucedeu o contágio da população, dissipando a pandemia para diferentes países do mundo (Yupari-Azabache, et al. 2020).

O contágio pelo vírus SARS-CoV-2 é uma das infecções mais recentes explanadas nas ciências médicas. Desde os relatórios iniciais, esse vírus trouxe consigo grande preocupação pela rapidez na sua transmissão e disseminação em menos de três meses (Despaigne, et al, 2020). O vírus se disseminou velozmente por toda a parte do mundo, com isso, a Organização Mundial de Saúde (OMS) no dia 11 de março de 2020 anunciou uma pandemia por conta do surto de uma nova doença chamada de Covid-19 (Vitale, et al. 2020).

As manifestações agudas do vírus podem envolver as vias pulmonares, cardiovascular, o sistema neurológico, gastrointestinal e hematológico, podendo persistir sintomas físicos após a Covid-19 como fadiga, dor no peito, dispneia, tosse e sintomas neuro cognitivos (Singh, et al. 2021). O coronavírus afeta as células epiteliais do trato respiratório, causando danos alveolar difuso, resultando no desequilíbrio do processo que realiza as trocas gasosas entre o meio ambiente e o organismo, impedindo a manutenção esperada da oferta de $\mathrm{O} 2$ e remoção de $\mathrm{CO} 2$ dos tecidos, resultando consequentemente na insuficiência respiratória aguda (Castro, et al. 2020).

Observa-se também que com a instalação de determinações básicas de proteção, como confinamento de indivíduos que foram ou não expostos ao vírus, tem sido associada a sintomas de estresse pós-traumático e ansiedade, esses tem sido evidenciado tanto em profissionais da saúde como na sociedade como um todo (Gómez, et al. 2020).

A qualidade de vida é a percepção do indivíduo de sua posição na vida de acordo com o ambiente no qual ele vive, de culturas e valores, relacionados aos seus objetivos e expectativas. Quando se refere à saúde, a qualidade de vida inclui a satisfação e o bem-estar de acordo com a concepção do paciente (Wiethan; Soares; Souza, 2017). falam que a OMS descreve qualidade de vida como o entendimento que o indivíduo tem acerca do seu bem-estar físico, social, mental e espiritual, em combinação com sua condição cultural, social e histórica. Dessa forma, seguindo essa definição a avaliação da qualidade de vida foi instalada como um meio de examinar os estados de saúde e bem-estar desde os anos 60 (Lostaunau, Torrejón e Cassaretto 1995).

A qualidade de vida é vista com um dos conteúdos com maior interdisciplinaridade na época atual, sendo bastante utilizada em publicações científicas. Esta passou a ser examinada na área, tanto em formas individuais, em grupo, como também em grandes populações. Seguindo esse pensamento, nos últimos anos a perspectiva do paciente em relação a sua doença, bem como a particularidade dos critérios terapêuticos utilizados e o seguimento do tratamento em sua vida tem obtido bastante reconhecimento, sendo considerado um dos maiores avanços na área da saúde (Souza 2011). 
O conhecimento quanto aos índices de qualidade de vida se transformou em um utensílio relevante na prática clínica por ser capaz de instruir uma melhor estratégia de intervenção e facilitar a verificação da repercussão da doença na perspectiva biopsicossocial do indivíduo (Aragão, et al. 2018).

Portanto, o estudo teve por objetivo a realização de uma revisão sistemática da literatura, analisando o impacto da Covid-19 na qualidade de vida e saúde dos pacientes pós-Covid-19.

\section{Metodologia (fonte TNR 12 - alinhado esquerda)}

O presente estudo trata-se de uma revisão sistemática com abordagem qualitativa registrada na Prospero com número de registro CRD42021282900, visando responder a seguinte pergunta clínica: "Qual o impacto da Covid-19 na qualidade de vida e saúde dos pacientes pós-Covid?”. Para responder essa pergunta, partiu-se da metodologia/estratégia PECO (Population/População; Exposure/Exposição; Comparison/Comparação; Outcomes/Desfecho).

P: Pacientes pós-covid-19;

E: Covid-19;

C: Nenhuma comparação;

O: Impacto na qualidade de vida e saúde.

Foi desenvolvido através de um levantamento literário científico, tendo como fonte artigos científicos nas bases de dados PEDro, BVS, Pubmed e Scielo, ERS (European Eespiratory Eociety), ATS, CHEST, SBPT (Jornal Brasileiro de Pneumologia) e ASSOBRAFIR, foram utilizados descritores contidos nos Descritores em Ciência da Saúde (DeCS) em combinação com os operadores booleanos "Covid-19" AND “qualidade de vida" AND "sars-cov-2" AND "coronavírus". Os artigos incluídos nos resultados foram limitados quanto ao ano, entre 2020 a 2021 e sem restrições de idioma.

Foram incluídos na pesquisa estudos observacionais que abordavam sobre o impacto da Covid-19 na qualidade de vida dos pacientes após a doença e excluídos artigos duplicados, outros tipos de estudo, que abordavam outra temática e aqueles que não mantiveram relação com o objetivo da pesquisa.

A seleção dos estudos para essa revisão foi realizada por dois revisores independentes começando pela triagem dos títulos e resumos para identificar se os artigos eram elegíveis, em seguida foi realizada a leitura completa dos textos e a avaliação dos critérios de inclusão para resultados mais criteriosos, após a coleta os artigos foram separados e discutidos entre os pesquisadores.

A avaliação da qualidade dos artigos selecionados foi realizada pela Newcastle Ottawa Scale (NOS), que avalia os estudos observacionais em oito itens divididos em três grupos, sendo quatro itens no grupo de seleção, um em comparabilidade e três no grupo resultado. Um estudo pode receber no máximo uma estrela para cada item no grupo de seleção e resultado, e no máximo duas estrelas para comparabilidade. Foram selecionados os artigos que tiveram boa qualidade, ou seja, aqueles que tiveram 3 ou 4 estrelas no domínio seleção, 1 ou 2 estrelas em comparabilidade e 2 ou 3 estrelas em resultado, ao final, para a construção dos resultados permaneceram os estudos que atenderam aos critérios de inclusão e elegibilidade da escala.

\section{Resultados}

A seleção dos estudos rastreados nas bases de dados supracitadas foi dividida em 3 etapas (Figura 1). A primeira foi caracterizada pela busca do material nas bases de dados, entre o período de setembro/2021 a outubro/2021, onde é encontrado um total de 44 artigos. A segunda etapa constou a seleção dos estudos através da verificação e análise dos resumos disponíveis, 
chegando a um total de 10 artigos. Por último, na terceira etapa, caso o estudo fosse selecionado, todo o seu conteúdo era lido na íntegra, na qual resultou em 7 trabalhos para compor esta revisão.

Figura 1. Fluxograma de pesquisa e triagem dos estudos relacionados nos bancos de dados, conforme a plataforma PRISMA. Teresina-PI, 2021

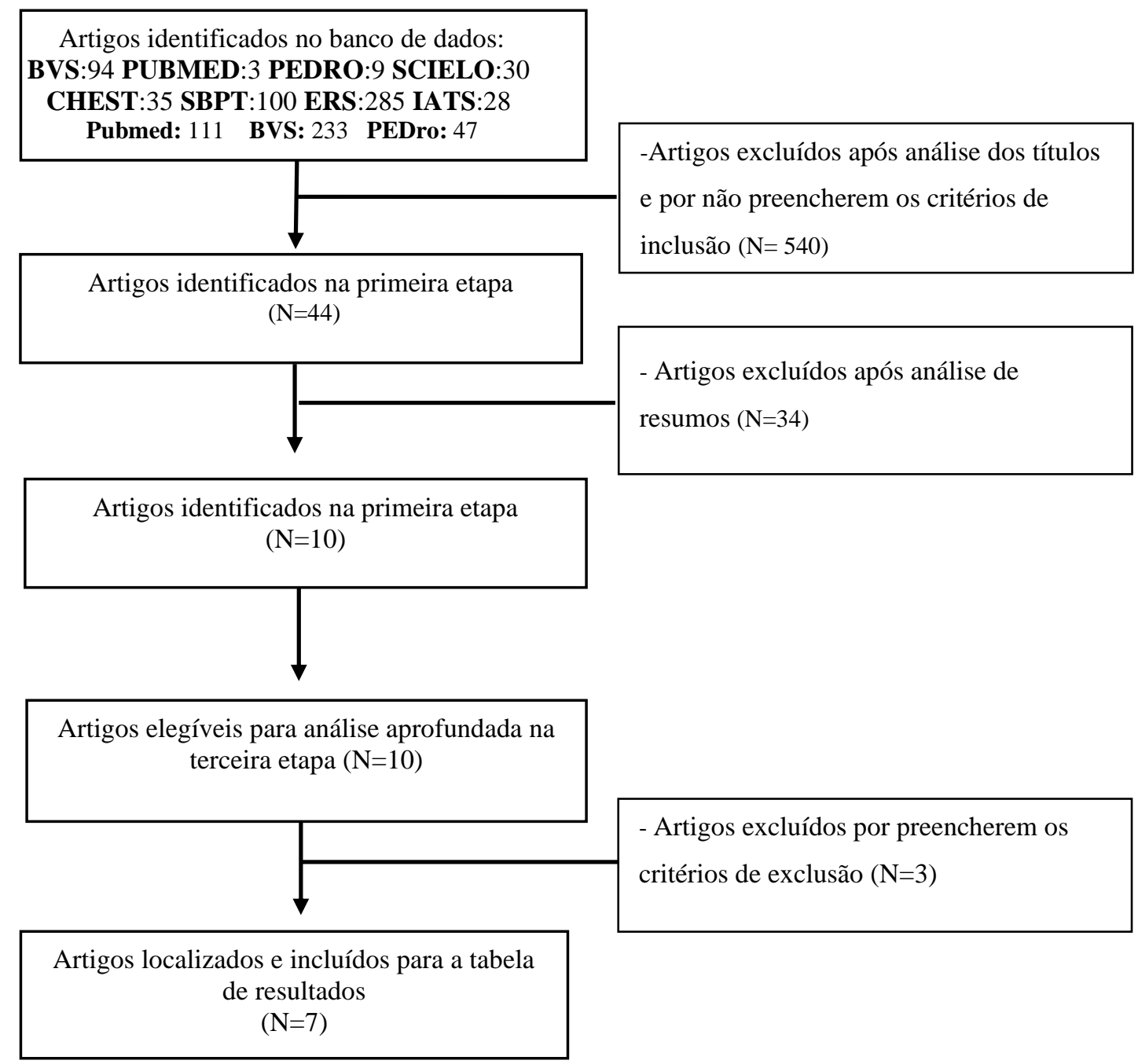

Fonte: Autoria própria dos pesquisadores.

A avaliação dos 7 artigos foi realizada pela Escala de Newcastle - Ottawa (NOS), e foram avaliados quanto a seleção, comparabilidade e desfecho. Todos os artigos obtiveram um total de 3 ou 4 estrelas no domínio seleção, 1 ou 2 estrelas em comparabilidade e 2 ou 3 estrelas em resultado, sendo assim, todos foram classificados como de boa qualidade (Quadro 1). 
Research, Society and Development, v. 10, n. 15, e542101523534, 2021

(CC BY 4.0) | ISSN 2525-3409 | DOI: http://dx.doi.org/10.33448/rsd-v10i15.23534

Quadro 1: Classificação dos estudos de coorte de acordo com a Escala de Newcastle - Ottawa (NOS). Teresina-PI, 2021

\begin{tabular}{|c|c|c|c|c|c|c|c|c|}
\hline \multirow[t]{2}{*}{ Estudo } & \multicolumn{4}{|c|}{ Seleção } & \multirow{2}{*}{$\begin{array}{c}\text { Comparabilida } \\
\text { de }\end{array}$} & \multicolumn{3}{|c|}{ Desfecho } \\
\hline & $\begin{array}{c}\text { Representativida } \\
\text { de da coorte } \\
\text { exposta }\end{array}$ & $\begin{array}{l}\text { Seleçã } \\
\text { o da } \\
\text { coorte } \\
\text { não } \\
\text { expost } \\
\text { a }\end{array}$ & $\begin{array}{l}\text { Verificaçã } \\
\text { o da } \\
\text { exposição }\end{array}$ & $\begin{array}{c}\text { Demonstraç } \\
\text { ão de que o } \\
\text { resultado de } \\
\text { interesse não } \\
\text { estava } \\
\text { presente no } \\
\text { início do } \\
\text { estudo }\end{array}$ & & $\begin{array}{l}\text { Avaliaçã } \\
\text { o do } \\
\text { resultad } \\
\quad \text { o }\end{array}$ & $\begin{array}{c}\text { O } \\
\text { acompanhamen } \\
\text { to foi longo o } \\
\text { suficiente para } \\
\text { que os } \\
\text { resultados } \\
\text { ocorressem }\end{array}$ & $\begin{array}{l}\text { Adequação de } \\
\text { acompanhamen } \\
\text { to de coortes }\end{array}$ \\
\hline $\begin{array}{l}\text { Walle- } \\
\text { Hansen } \\
\text { et al., } \\
2021 .\end{array}$ & is & & is & is & is & is & 㶦 & 访 \\
\hline $\begin{array}{l}\text { Huang } \\
\text { et al., } \\
2021 .\end{array}$ & is & 㶦 & is & is & 论弥 & is & it & it \\
\hline $\begin{array}{l}\text { Todt et } \\
\text { al., } \\
2021 .\end{array}$ & is & & is & is & 论弥 & & is & is \\
\hline $\begin{array}{l}\text { Van der } \\
\text { Sar - } \\
\text { van der } \\
\text { Brugge } \\
\text { et al., } \\
2020 \text {. }\end{array}$ & 岤 & . & is & is & 论弥 & is & 岤 & is \\
\hline $\begin{array}{l}\text { Vlake } \\
\text { et al., } \\
2021 .\end{array}$ & it & 㶦 & is & is & 论败 & & 式 & 式 \\
\hline $\begin{array}{l}\text { Huang } \\
\text { et al., } \\
2021 .\end{array}$ & 弐 & & is & is & 论败 & is & 㶦 & is \\
\hline $\begin{array}{l}\text { Bardak } \\
\text { ci et al., } \\
2021 .\end{array}$ & 㶦 & & is & is & 论败 & 㶦 & 㶦 & 访 \\
\hline
\end{tabular}

Fonte: Autoria própria dos pesquisadores.

No quadro 2 em seguida, é destacado a caracterização dos estudos incluídos na presente revisão sistemática, dividindo os mesmos nas seguintes características: Autor/ano; Tipo de estudo; Exposição; Descrição da Amostra; Instrumentos de coleta de dados e Principais resultados. Nos resultados abaixo mostram que a Covid-19 provoca alterações na qualidade de vida dos pacientes de formas diferentes e cada autor mostra as particularidades do seu estudo que influenciam nos resultados finais. 
Research, Society and Development, v. 10, n. 15, e542101523534, 2021

(CC BY 4.0) | ISSN 2525-3409 | DOI: http://dx.doi.org/10.33448/rsd-v10i15.23534

Quadro 2: Dados gerais dos artigos selecionados para os resultados. Teresina-PI, 2021.

\begin{tabular}{|c|c|c|c|c|c|}
\hline $\begin{array}{c}\text { Autor/An } \\
\quad 0\end{array}$ & $\begin{array}{l}\text { Tipo de } \\
\text { estudo }\end{array}$ & Exposição & Descrição da Amostra & $\begin{array}{l}\text { Instrumentos de } \\
\text { coleta de dados }\end{array}$ & Principais resultados \\
\hline $\begin{array}{l}\text { Walle- } \\
\text { Hansen et } \\
\text { al., } 2021\end{array}$ & $\begin{array}{c}\text { Estudo de } \\
\text { coorte } \\
\text { multicêntrico. }\end{array}$ & Covid-19. & $\begin{array}{l}106 \text { pacientes com } 60 \\
\text { anos ou mais que foram } \\
\text { internados em quatro } \\
\text { hospitais gerais no } \\
\text { sudeste da Noruega } \\
\text { devido ao COVID19 de } \\
1^{\circ} \text { de março a } 1^{\circ} \text { de } \\
\text { julho de } 2020 .\end{array}$ & $\begin{array}{c}\text { Foram avaliados } \\
\text { usando o EuroQol } 5 \\
\text { dimensional-5 } \\
\text { níveis, a Avaliação } \\
\text { Cognitiva de } \\
\text { Montreal (MoCA), } \\
\text { e o Short Physical } \\
\text { Bateria de } \\
\text { desempenho } \\
\text { (SPPB). }\end{array}$ & $\begin{array}{l}57 \text { participantes (54\%) relataram uma } \\
\text { diminuição no EQ. 5D-5L após } 6 \text { meses, } \\
70 \text { participantes (66\%) relataram uma } \\
\text { mudança negativa em qualquer uma das } \\
\text { dimensões do EQ. 5D-5L. A capacidade } \\
\text { prejudicada de realizar atividades da vida } \\
\text { diária (35\%), mobilidade reduzida (33\%) } \\
\text { e sentir mais dor ou desconforto (33\%) } \\
\text { são as alterações mais comumente } \\
\text { relatadas. } 46 \text { participantes (43\%) } \\
\text { relataram uma mudança negativa na } \\
\text { função cognitiva em comparação com } \\
\text { antes da hospitalização por COVID-19 }\end{array}$ \\
\hline $\begin{array}{l}\text { Huang et } \\
\text { al., } 2021 \text {. }\end{array}$ & $\begin{array}{c}\text { Estudo de } \\
\text { coorte } \\
\text { ambidireciona } \\
1 .\end{array}$ & Covid-19. & $\begin{array}{l}1.276 \text { sobreviventes } \\
\text { receberam alta do } \\
\text { Hospital Jin Yin-tan } \\
\text { (Wuhan, China) entre } 7 \\
\text { de janeiro e } 29 \text { de maio } \\
\text { de } 2020 . \text { Houve divisão } \\
\text { em coorte exposta à } \\
\text { Covid-19 e coorte não } \\
\text { exposta. }\end{array}$ & $\begin{array}{l}\text { Foram submetidos } \\
\text { a uma entrevista } \\
\text { detalhada, exame } \\
\text { físico e teste de } \\
\text { caminhada de } 6 \\
\text { minutos, } \\
\text { responderam a } \\
\text { Escala de dispneia } \\
\text { do Medical } \\
\text { Research Council } \\
\text { (mMRC) e } \\
\text { EuroQol. }\end{array}$ & $\begin{array}{c}\text { Sobreviventes de Covid-19 } \\
\text { correspondentes aos } 12 \text { meses tiveram } \\
\text { mais problemas com mobilidade, dor ou } \\
\text { desconforto e ansiedade ou depressão, e } \\
\text { tiveram sintomas mais prevalentes do que } \\
\text { os controles. A maioria dos sobreviventes } \\
\text { de Covid-19 teve uma boa recuperação } \\
\text { física e funcional durante o } \\
\text { acompanhamento de } 1 \text { ano, voltaram ao } \\
\text { seu trabalho e vida originais. O estado de } \\
\text { saúde em nossa coorte de sobreviventes } \\
\text { de Covid-19 aos } 12 \text { meses ainda era } \\
\text { menor do que na população de controle. }\end{array}$ \\
\hline $\begin{array}{r}\text { Todt et } \\
\text { al., } 2021 .\end{array}$ & $\begin{array}{l}\text { Estudo de } \\
\text { coorte } \\
\text { unicêntrico. }\end{array}$ & Covid-19. & $\begin{array}{c}251 \text { pacientes que } \\
\text { receberam alta um e três } \\
\text { meses do Hospital } \\
\text { Municipal Dr. Moys'es } \\
\text { Deutsch (São Paulo, } \\
\text { Brasil). }\end{array}$ & $\begin{array}{l}\text { Foram contactados } \\
\text { por telefone e } \\
\text { submetidos a } \\
\text { responderem o } \\
\text { questionário de } \\
\text { qualidade de vida } \\
\text { EQ-5D (EQ-5D- } \\
\text { 3L). }\end{array}$ & $\begin{array}{l}\text { Os pacientes relataram um piora geral do } \\
\text { índice de resumo único EQ-5D-3L em } 3 \\
\text { meses em comparação com antes do início } \\
\text { do Covid-19 sintomas }(0,8012(0,7368 \text { - } \\
\text { 1,0) vs. } 1,0(0,7368-1,0), p<0,001) \text {. Isso } \\
\text { afetou todos os } 5 \text { domínios, mas } \\
\text { especialmente dor / desconforto e } \\
\text { ansiedade / depressão. }\end{array}$ \\
\hline $\begin{array}{l}\text { Van der } \\
\text { Sar - van } \\
\quad \text { der } \\
\text { Brugge et } \\
\text { al., 2021. }\end{array}$ & $\begin{array}{l}\text { Estudo de } \\
\text { coorte } \\
\text { longitudinal } \\
\text { prospectivo. }\end{array}$ & Covid-19 & $\begin{array}{c}101 \text { pacientes } \\
\text { descarregados entre } 16 \\
\text { de março e } 15 \text { de abril } \\
\text { de } 2020 \text { de Amphia } \\
\text { Hospital (Breda, } \\
\text { Holanda) após RT-PCR } \\
\text { confirmado. }\end{array}$ & $\begin{array}{l}\text { Realizaram exame } \\
\text { físico, teste de } \\
\text { função pulmonar e } \\
\text { preencheram } \\
\text { questionários } \\
\text { avaliando HRQoL } \\
\text { (SF-36), dispneia e } \\
\text { sintomas de } \\
\text { depressão e } \\
\text { ansiedade (HADS). }\end{array}$ & $\begin{array}{l}\text { Em todos os domínios do SF-36, exceto } \\
\text { para dor corporal, foi encontrado } \\
\text { comprometimento significativo. } \\
\text { Limitação de difusão (DLCOc }<80 \% \text { do } \\
\text { valor previsto) foi encontrada em } 66 \\
(71,7 \%) \text { de } 92 \text { casos, obstrução em } 26 \\
(25,7 \%) \text { de } 101, \text { e restrição em } 21(21,2 \%) \\
\text { de } 99 \text {. A capacidade de difusão foi } \\
\text { significativamente menor nos casos após } \\
\text { pneumonia grave. Em todo o grupo, } \\
\text { pontuações HADS } \geq 8 \text { para depressão } \\
\text { foram encontradas em } 16,6 \% \text { e em } 12,5 \% \\
\text { para ansiedade. }\end{array}$ \\
\hline $\begin{array}{l}\text { Vlake et } \\
\text { al., } 2021 .\end{array}$ & $\begin{array}{l}\text { Estudo de } \\
\text { coorte } \\
\text { observacional } \\
\text { de centro } \\
\text { único. }\end{array}$ & Covid-19 & $\begin{array}{l}294 \text { pacientes maiores } \\
\text { de } 18 \text { anos que foram } \\
\text { hospitalizados } 16 \text { de } \\
\text { março e } 28 \text { de abril de } \\
2020 \text { com sintomas } \\
\text { sugestivos de Covid-19 } \\
\text { que foram divididos em } \\
\text { uma coorte exposta à } \\
\text { Covid-19 e não exposta } \\
\text { e em pacientes Covid- } \\
19 \text { UTI e não UTI. }\end{array}$ & $\begin{array}{c}\text { Responderam a } \\
\text { Escala HADS, } \\
\text { questionário IES-R, } \\
\text { HRQoL e RAND- } \\
36 .\end{array}$ & $\begin{array}{l}\text { 16\% e } 13 \% \text { desses pacientes relataram } \\
\text { provável PTSD, } 29 \% \text { e } 20 \% \text { provável } \\
\text { ansiedade e } 32 \% \text { e } 24 \% \text { provável } \\
\text { depressão em um e três meses após a alta } \\
\text { hospitalar. Pacientes Covid-19 tiveram } \\
\text { uma piora física na qualidade de vida um } \\
\text { mês após a alta, e os pacientes da UTI } \\
\text { relataram uma melhor qualidade mental } \\
\text { de vida três meses após a alta. }\end{array}$ \\
\hline
\end{tabular}


Research, Society and Development, v. 10, n. 15, e542101523534, 2021

(CC BY 4.0) | ISSN 2525-3409 | DOI: http://dx.doi.org/10.33448/rsd-v10i15.23534

\begin{tabular}{|c|c|c|c|c|c|}
\hline $\begin{array}{l}\text { Huang et } \\
\text { al., } 2021 .\end{array}$ & $\begin{array}{c}\text { Estudo de } \\
\text { coorte } \\
\text { ambidireciona } \\
1 .\end{array}$ & Covid-19. & $\begin{array}{l}1.733 \text { pacientes que } \\
\text { receberam alta } \\
\text { hospitalar entre } 7 \text { de } \\
\text { janeiro e de } 2020 \text { e } 29 \\
\text { de maio de } 2021 \\
\text { divididos em escala de } \\
\text { gravidade } 3 \text {, gravidade } \\
4 \text { e gravidade } 5-6 .\end{array}$ & $\begin{array}{l}\text { Realizaram exame } \\
\text { físico, teste de } \\
\text { caminhada de } 6 \\
\text { minutos, exames de } \\
\text { sangue e } \\
\text { responderam os } \\
\text { questionários } \\
\text { Modified British } \\
\text { Medical Research } \\
\text { Council (mMRC) } \\
\text { escala de dispneia, } \\
\text { EuroQol, e um } \\
\text { formulário de } \\
\text { registro de acidente } \\
\text { vascular cerebral } \\
\text { isquêmico e evento } \\
\text { cardiovascular. }\end{array}$ & $\begin{array}{c}\text { Fadiga ou fraqueza muscular }(63 \%, 1.038 \\
\text { de } 1655) \text { e dificuldades para dormir }(26 \%, \\
437 \text { de } 1655) \text { foram os sintomas mais } \\
\text { comuns, ansiedade ou depressão foi } \\
\text { relatada entre } 23 \% \text { ( } 367 \text { de } 1617 \text { ) dos } \\
\text { pacientes. As proporções da caminhada } \\
\text { mediana de } 6 \text { minutos distância menor } \\
\text { que o limite inferior da faixa normal foi } \\
\text { de } 24 \% \text { para aqueles na escala de } \\
\text { gravidade } 3,22 \% \text { para a escala de } \\
\text { gravidade } 4 \text { e } 29 \% \text { para a escala de } \\
\text { gravidade 5-6. }\end{array}$ \\
\hline $\begin{array}{l}\text { Bardakci } \\
\text { et al., } \\
2021 .\end{array}$ & $\begin{array}{l}\text { Estudo de } \\
\text { coorte. }\end{array}$ & Covid-19 & $\begin{array}{l}65 \text { pacientes maiores de } \\
18 \text { anos acompanhados } \\
\text { entre } 11 \text { de março e } 30 \\
\text { de julho de } 2020 .\end{array}$ & $\begin{array}{l}\text { Realizaram } \\
\text { espirometria, teste } \\
\text { de caminhada de } 6 \\
\text { minutos, TC de } \\
\text { tórax e } \\
\text { responderam ao } \\
\text { questionário de } \\
\text { qualidade de vida } \\
\text { SF-36. }\end{array}$ & $\begin{array}{l}\text { Na escala SF-36, função física, energia - } \\
\text { vitalidade, funcionalidade social, dor e } \\
\text { parâmetros gerais de saúde foram } \\
\text { encontrados mais baixo do que o normal. } \\
\text { Alterações intersticiais mínimas na TC de } \\
\text { tórax foram observadas em } 26 \text { pacientes. } \\
\text { Nove pacientes tiveram envolvimento da } \\
\text { área pulmonar entre } 10 \% \text { e } 50 \% \text { da } \\
\text { superfície. }\end{array}$ \\
\hline
\end{tabular}

Fonte: Autoria própria dos autores.

\section{Discussão}

Para essa revisão foram encontrados sete artigos que avaliaram o impacto da covid-19 na qualidade de vida de pacientes pós-Covid-19. Os achados mostraram uma prevalência de idade de 50 anos ou mais, tanto do sexo feminino como masculino, todos os pacientes foram internados na UTI ou não UTI e submetidos ou não à ventilação mecânica, além de apresentarem complicações pela covid-19.

Os achados relacionados à fatores psicológicos mostraram que os pacientes apresentaram depressão, ansiedade e PTSD (Perturbação de estresse pós-traumático), corroborando com Huang et al. (2021), Told et al. (2021), Van der Sar- Van der Brugge et al. (2021), Vlake et al. (2021), Huang et al. (2021). Os resultados mostram que a piora física foi um fator comum entre os pacientes, onde apresentaram mobilidade reduzida, fraqueza ou fadiga muscular e dificuldade de realizar as atividades de vida diária, sendo melhor descritos nos estudos de Walle- Hansen et al. (2021), Huang et al. (2021), Vlake et al. (2021) e Huang et al. (2021).

Van der Sar- Van der Brugge et al (2021) mostrou em seus resultados que os pacientes apresentaram comprometimento em todos os domínios do SF-36, exceto dor corporal, divergindo com os estudos de Wallen - Hansen et al. (2021), Huang et al. (2021), Todt et al. (2021) que mostraram que os participantes tiveram piora significativa tanto na dor quanto no desconforto. No estudo de Huang et al. (2021), 26\% dos pacientes relataram dificuldade de dormir entre os sintomas mais comuns, o que não foi exposto em nenhum outro estudo.

A função cognitiva também foi um achado importante, Walle-Hansen et al. (2021) demonstra em seu estudo que nesse fator houve uma mudança negativa em $43 \%$ dos pacientes comparado a antes da internação por Covid-19. No estudo de Bardakci et al. (2021), além das características relacionadas à qualidade de vida, os participantes apresentaram também comprometimento pulmonar, que consequentemente pode alterar a qualidade de vida.

Os resultados entre os estudos são semelhantes, porém aqueles com maior tempo de acompanhamento como Huang et 
al. (2021) pode haver resultados ainda mais concretos, diferente de Vlake et al. (2021) e Van der Sar-Van der Brugge et al. (2021) por exemplo, que acompanharam por um período menor, podendo os sintomas se manifestarem depois do período proposto. Nos estudos de Todt et al. (2021) e Vlake et al. (2021) os pacientes fizeram autorrelato, podendo também gerar risco de viés e interferir nos resultados.

Os estudos não fizeram comparações entre grupo exposto e não exposto, exceto Vlake et al. (2021) e Huang et al. (2021), no entanto, os resultados se divergem, pois, os pacientes do estudo de Vlake et al. (2021) demonstraram alterações na qualidade de vida, mas não obtiveram diferenças entre os grupos exposto e não exposto e nem entre os grupos Covid-19 UTI e não UTI, já o de Huang et al. (2021) houve diferença entre os grupos, o grupo exposto tinha um estado de saúde pior em relação ao grupo não exposto.

No geral, todos os autores mostram em seus estudos que a Covid-19 provoca alterações na qualidade de vida e saúde dos pacientes, e afeta de formas diferentes, dependendo da gravidade da doença, se ela está associada a complicações provocada pela Covid-19, se o paciente foi submetido à ventilação mecânica ou não e dependendo também das próprias características dos pacientes que podem influenciar na gravidade da doença, em relação à idade, condições pré-existentes, entre outros.

\section{Conclusão}

Esta revisão explorou o impacto que a Covid-19 tem na qualidade de vida e saúde dos pacientes após a doença, onde mostrou que os pacientes após a alta tiveram piora significativa na saúde em todos os aspectos das escalas de qualidade de vida, na capacidade funcional, mostrou que os pacientes apresentaram depressão, ansiedade, estresse pós-traumático, além de outros fatores prejudiciais à saúde que permaneceram mesmo após alguns meses depois da doença, desta forma, mostrando a importância e o cuidado que se deve ter à Covid-19 e as consequências que ela pode causar na vida da população, contribuindo então na evolução para futuras pesquisas sobre o tema.

\section{Referências}

Aragão, José Aderval et al. (2018). Qualidade de vida em pacientes com doença arterial periférica. Jornal Vascular Brasileiro, 17 (2), $117-121$.

Bardakci, Mustafa Ilteris et al. (2021). Evaluation of long-term radiological findings, pulmonary functions, and health-related quality of life in survivors of severe COVID-19. Journal Of Medical Virology, 93 (9), 5574-5581.

Castro, Bruno Magalhães et al. (2021). The impact of quarantine on body image and lifestyle habits in resistance training practitioners. Revista Brasileira de Medicina do Esporte, 27 (1), 16-20.

Despaigne, D. A. N. et al. (2020). Una mirada biológico-social en las características clínicas de adultos cubanos infectados por el virus SARS CoV2. SciELO Preprints, 1-21.

Durmus, Ensar; Guneysu, Fatih (2020). Evaluation of re-hospitalized COVID-19 patients in a hospital. Associação Médica Brasileira, 66 (12), $1690-1695$.

Gómez, Jorge Arturo Martínez et al. (2020). Tendencias de la investigación sobre sintomas de transtornos mentales durante la pandemia por covid-19. Medicina $U P B, 39(2), 24-33$.

Huang, Chaolin et al. (2021) 6-month consequences of COVID-19 in patients discharged from hospital: a cohort study. The Lancet, 397 (10270), $220-232$.

Huang, Lixue et al. (2021). 1-year outcomes in hospital survivors with COVID-19: a longitudinal cohort study. The Lancet, 398 (10302), 747-758.

Lostaunau, Vanessa; Torrejón, Claudia; Massaretto, Mónica (2017). Estrés, afrontamiento y calidad de vida relacionada a la salud en mujeres con cáncer de mama. Actualidades en Psicología, 31 (122), 75-90.

Singh, Inderjit et al. (2021). Persistent Exertional Intolerance After COVID-19: Insights From Invasive Cardiopulmonary Exercise Testing. CHEST, 160 (4), 1-10.

Souza, Teresinha de Jesus Abreu (2011). Qualidade de vida do paciente internado em uma unidade de queimados. Revista Brasileira de Cirurgia Plástica, 26 (1), $10-15$.

Todt, Beatriz costa et al. (2021). Clinical outcomes and quality of life of COVID-19 survivors: A follow-up of 3 months post hospital discharge. Respiratory Medicine, 184 (106453), 1-8. 
Research, Society and Development, v. 10, n. 15, e542101523534, 2021

(CC BY 4.0) | ISSN 2525-3409 | DOI: http://dx.doi.org/10.33448/rsd-v10i15.23534

Urrego, C. C. A. et al. (2020). Papel de las pruebas rápidas (POCT) en el diagnóstico del SARS-COV-2, agente causal de COVID-19. Nova, 18 (35), 41-50.

Van der Sar - Van der Brugge, S. et al. (2021). Pulmonary function and health-related quality of life after COVID-19 pneumonia. Respiratory Medicine, 176 (106272), 1-4.

Vitale, Jacopo Antonino (2020). Home-based resistance training for older subjects during the covid-19 outbreak in italy: Preliminary results of a six-months RCT. International Journal of Environmental Research and Public Health, 17, (24), 1-15.

Vlake, Johan Hendrik et al. (2021). Psychological distress and health-related quality of life in patients after hospitalization during the COVID-19 pandemic: A singlecenter, observational study. Plos One, $16(8), 1-22$.

Walle-Hansen, M. M. et al. (2021). Health-related quality of life, functional decline, and long-term mortality in older patients following hospitalisation due to COVID-19. BMC Geriatrics, 21 (199), 1-10.

Wiethan, J.V; Soares, J. C.; Souza, J. A. (2017). Avaliação da funcionalidade e qualidade de vida em pacientes críticos: série de casos. Acta Fisiátrica, 24 (1), 7 12.

Yokoo, Patrícia et al. (2020). Miocardite na COVID-19: um relato de caso. Einstein, 18, 1-5.

Yupari-Azabache, Irma et al. (2021). Factores de riesgo de mortalidad por covid-19 en pacientes hospitalizados: un modelo de regresión logística. Revista de la Facultad de Medicina Humana, 21 (1), 19-27. 